\title{
PROFITABILITY OF MOMENTUM \\ STRATEGIES: AN EVALUATION \\ OF ALTERNATIVE EXPLANATIONS
}

\author{
Narasimhan Jegadeesh \\ Sheridan Titman
}

Working Paper 7159

http://www.nber.org/papers/w7159

\author{
NATIONAL BUREAU OF ECONOMIC RESEARCH \\ 1050 Massachusetts Avenue \\ Cambridge, MA 02138 \\ June 1999
}

This paper has benefited from the excellent research assistance of Fei Zou and helpful comments from the participants of finance workshops at Indiana University and the University of Texas. All opinions expressed are those of the authors and not those of the National Bureau of Economic Research.

(C) 1999 by Narasimhan Jegadeesh and Sheridan Titman. All rights reserved. Short sections of text, not to exceed two paragraphs, may be quoted without explicit permission provided that full credit, including (C) notice, is given to the source. 
Profitability of Momentum Strategies:

An Evaluation of Alternative Explanations

Narasimhan Jegadeesh and Sheridan Titman

NBER Working Paper No. 7159

June 1999

JEL No. G12

\section{ABSTRACT}

This paper evaluates various explanations for the profitability of momentum strategies documented in Jegadeesh and Titman (1993). The evidence indicates that momentum profits have continued in the 1990's suggesting that the original results were not a product of data snooping bias. The paper also examines the predictions of recent behavioral models that propose that momentum profits are due to delayed overreactions which are eventually reversed. Our evidence provides support for the behavioral models, but this support should be tempered with caution. Although we find no evidence of significant return reversals in the 2 to 3 years following the following formation date, there are significant return reversals 4 to 5 years after the formation date. Our analysis of posthiding period returns sharply rejects a claim in the literature that the observed momentum profits can be explained completely by the cross-sectional dispersion in expected returns.

Narasimhan Jegadeesh

Department of Finance

College of Commerce and Business

University of Illinois

1206 S. Sixth Street

Champaign, IL 61820-6980

jegadees@uiuc.edu
Sheridan Titman

Department of Finance

University of Texas

Austin, TX 78712-1179

and NBER

titman@mail.utexas.edu 
Many portfolio managers and stock analysts subscribe to the view that momentum strategies yield significant profits. Jegadeesh and Titman (1993) (JT) examine a variety of momentum strategies and document that strategies that buy stocks with high returns over the previous 3 to 12 months and sell stocks with poor returns over the same time period earn profits of about one percent per month. ${ }^{1}$ While these results have been well accepted, the source of the profits and the interpretation of the evidence are widely debated. While some have argued that the results provide strong evidence of "market inefficiency," others have argued that the returns from these strategies are either compensation for risk, or alternatively, the product of data mining.

The criticism that observed empirical regularities arise because of data mining is typically the hardest to address since empirical research in non-experimental settings is limited by data availability. Fortunately, with the passage of time, we now have eight additional years of data for out of sample tests. Using the data over the 1990 to 1997 sample period, we find that JT momentum strategies continue to be profitable and the past winners outperform past losers by about the same magnitude as in the earlier period. In addition, the January seasonality documented by JT is also observed in the more recent sample period. This is noteworthy given that other well-known anomalies such as the small firm effect documented by Banz (1981) and the superior performance of growth stocks relative to value stocks do not obtain in subsequent sample periods. ${ }^{2}$

Given the persistence of this anomaly, it is important to understand its cause. A number of authors, e.g., Barberis et al (1998), Daniel et al. (1998) and Hong and Stein (1998) present behavioral models that are based on the idea that momentum profits arise because of inherent biases in the way that investors interpret information. Others, however, have argued that it is premature to reject the rational models and suggest that the profitability of momentum strategies may simply be compensation for risk. Most notably, Conrad and Kaul (1998) (CK) argue that the profitability of momentum strategies could be entirely due to cross-sectional variations in mean

\footnotetext{
${ }^{1}$ Rowenhorst (1998) reports that the momentum profits documented by Jegadeesh and Titman (1993) for the U.S. market also obtains in the European markets. Grinblatt and Moskowitz (1999) and Grundy and Martin (1999) examine the industry and factor components of momentum profits. See Haugen (1999) for additional discussion of the momentum effect.

${ }^{2}$ The average of the Fama-French size factor in the sample period 1965 to 1981 (which precedes the publication of Banz (1981)) is $.53 \%$ per month with a $t$-statistic of 2.34. In the 1982 to 1997 sample period the average size factor is $-.09 \%$ with a $t$-statistic of -.37 . Similarly, the average Fama-French book-to-market factor in the sample period 1965 to 1989 is $.51 \%$ per month ( $t$-statistic of 2.61). However, in the 1990 to 1997 period, which is after the sample period in Fama and French (1993), the average book-to-market factor return is .19\% per month ( $t$-statistic of .76) which is not statistically different from zero.
} 
returns rather than to any predictable time-series variations in stock returns. Specifically, following Lo and MacKinlay (1990) and others, they note that stocks with high (low) unconditional expected rates of return in adjacent time periods are expected to have high (low) realized rates of returns in both periods. Hence, momentum strategies will yield positive average returns even if the expected returns on stocks are constant over time.

The behavioral models and Conrad and Kaul's argument provide opposite predictions about the returns of past winners and losers over the period following the portfolio-holding period. The behavioral models specify that the holding period returns arise because of a delayed overreaction to information that push the prices of winners (losers) above (below) their long-term values. These models predict that the returns of losers should exceed the returns of winners subsequent to the holding period. In contrast, Conrad and Kaul (1998) suggest that the higher returns of winners in the holding period represent their unconditional expected rates of return and thus predict that the post-formation returns of the momentum portfolio will be positive on average in any post-ranking period.

To test the conflicting implications of these theories we examine the long-term returns of the winner and loser stocks in the momentum portfolio. Specifically, we examine the returns in each of the 60 months following the formation date. Over the entire sample period of 1965 to 1997 the cumulative return in months 13 to 60 for the JT momentum portfolio is negative. This finding supports the behavioral models but clearly rejects the Conrad and Kaul hypothesis which suggests that the winners will continue to outperform the losers outside the momentum strategy holding period.

Although the negative post-formation returns of the momentum portfolio appear to support the predictions of the behavioral models, based on our further analysis, we suggest that this support be interpreted with caution. First, we find no evidence of return reversals in the second and third year following the formation date. Evidence of return reversals exist only in the fourth and fifth years following the formation date. In addition, while we find strong evidence of return reversals in the 1965 to 1981 time period, the evidence of return reversals are substantially weaker in the 1982 to 1997 time period. This is noteworthy since there is no distinguishable difference between the magnitude or significance of the momentum profits in two subperiods. the post-formation returns are very different. They are significantly negative in the 1965 to 1981 period, but are essentially zero in the 1982 to 1997 period. Our evidence also indicates that at 
least a part of this difference in post-formation returns is due to differences in size and book-tomarket factor realizations in the two subperiods.

The negative post-holding returns of the momentum portfolio is somewhat surprising given the simulations presented in Conrad and Kaul (1998) that provide strong support for their

argument. To reconcile these conflicting findings we reexamine the Conrad and Kaul simulation and find a flaw in their experimental design. Our own simulations that correct this flaw indicates that very little, if any, of the momentum profits are due to the cross-sectional variation in mean returns.

The remainder of the paper is organized as follows: Section II provides a brief description of our data and methodology and examines the profitability of momentum strategies in the 1990s. Section III provides an analysis of the longer horizon returns. Section IV evaluates the contribution of cross-sectional variation in expected returns to momentum profits and Section $\mathrm{V}$ concludes the paper.

\section{Momentum Profits in the 1990s}

This section examines whether the profitability of the momentum strategies documented by JT can be attributed to data mining. The issue here is fairly straightforward. Stock return data are now widely available and computing power is fairly cheap. Since there are potentially large payoffs to any viable model that predicts stock returns (in terms of publications and/or money management revenues) many academics and practitioners have no doubt independently tested a wide variety of trading strategies. Therefore, it is difficult to assess the significance of individual studies that find that a particular trading strategy is profitable.

We address the data mining issue in the context of the JT six-month momentum strategy, which was previously shown to earn abnormal returns of about one percent per month with a $t$ statistic of 3.07 over the 1965 to 1989 sample period. When this strategy is viewed as a single experiment, standard statistical theory indicates that the probability of observing a $t$-statistic at least as large as 3.07 under the hypothesis of market efficiency is less than $0.11 \%$. Based on this, JT conclude that the hypothesis of market efficiency can be rejected at even the most conservative levels of significance. This inference, however, ignores the fact that there were many other tests independently carried out by other researchers over the same sample period that were perhaps not profitable and hence not reported. The fact that the evidence of momentum profits gained 
attention can be attributed to the fact that it yielded the highest test statistic among the many tests that were carried out collectively. Under this interpretation, the test statistic in Jegadeesh and Titman should be viewed as the highest order statistic across many tests rather than the conventional test statistic from a single experiment. The distribution of this order statistic of course is not normal.

To formalize that statistical analysis, suppose that researchers collectively tested $n$ independent trading strategies during the JT sample period. ${ }^{3}$ Also, suppose that the momentum strategy yielded the highest test statistic among these $n$ strategies. The cumulative distribution of the largest order statistic is $F^{n}$, where $F$ is the cumulative standard normal distribution. ${ }^{4}$ As stated earlier, if the JT test is viewed in isolation then $n=1$ and the probability of observing a $t$-statistic this large is $.11 \%$. However, if for example $n=100$, then the probability that the largest test statistic is at least 3.07 is about $10 \%$. If $n=650$, then the $p$-value based on this test statistic drops below $50 \%$. So the perception of how strong the JT evidence is in rejecting the efficient market hypothesis depends on the readers' priors about how many other independent and unreported tests that failed to reject market efficiency had been carried out.

The advantage of an out-of-sample test is that it significantly reduces the number of strategies that researchers can potentially search over, greatly reducing $n$, and thus increasing the informativeness of the tests. For this reason, we replicate the Jegadeesh and Titman (1993) strategy, and construct momentum portfolios as follows: We follow JT and include all NYSE/AMEX stocks and exclude NASDAQ stocks. We also exclude all stocks priced below \$5 at the beginning of the holding period. ${ }^{5}$ At the end of each month we rank the stocks in the sample based on their past six-month returns (month -5 to month 0 ) and then group the stocks into ten equally weighted portfolios based on these ranks. Each portfolio is held for six months (month 1 to month 6) following the ranking month. The various periods we consider are presented in the time line below, which also presents a post-holding period (month 13 to month

\footnotetext{
${ }^{3}$ The distribution of the highest order statistic will have to be numerically computed if the $n$ trading strategies examined in this sample period are correlated.

${ }^{4}$ We are assuming here that the degrees of freedom for the $t$-statistic is sufficiently large so that the $t$ distribution can be approximated by the standard normal distribution.

${ }^{5}$ Conrad and Kaul (1993) point out that much of the evidence of long horizon mean reversion in DeBondt and Thaler (1985) is due to the inclusion of low priced stocks. We screen out these low priced stocks to ensure that our results are not driven by extreme price movements in these low priced stocks The momentum profits are similar with or without the $\$ 5$ price screen except in Januarys. The low priced exhibit large return reversals in January and as a result the momentum strategies earn ląrger negative returns in January if these stocks are included. When all calendar months are considered, momentum profits are about one percent with or without the $\$ 5$ price screen.
} 
24) that we consider in the next section.

\section{Formation Period $\quad$ Holding Period $\quad$ Post-Holding Period}

\section{(Month -5 to Month 0) (Month 1 to Month 6 or 12) (Month 13 to Month 60)}

To increase the power of our tests we construct overlapping portfolios. In other words, a momentum decile portfolio in any particular month holds stocks ranked in that decile in any of the previous six ranking months. For instance, a December winner portfolio comprises ten percent of the stocks with the highest returns over the pervious June to November period, the previous May to October and so on up to the previous January to June Period. Each monthly cohort is assigned an equal weight in this portfolio.

\section{A. Holding Period Returns}

Table 1 presents the monthly returns for the ten momentum portfolios. Portfolio P1 is comprised of stocks with the best ranking period returns and P10 is comprised of stocks with the worst ranking period returns. The table reveals a monotonic relation between returns and momentum ranks over the 1965 to 1989 sample period, confirming the results in JT. The difference between the P1 and P10 portfolio returns is $1.11 \%$ per month, which is reliably different from zero. ${ }^{6}$

The table reveals that this return pattern continues in the more recent 1990 to 1997 period. In this more recent period, past winners outperform past losers by $1.01 \%$ per month, which is very close to the corresponding returns in the original JT sample period. One difference in the nineties is that the intermediate momentum portfolios do not exhibit the monotonic relation between decile ranks and returns found by JT. This is likely due to the fact that with only eight years of data expected returns are measured much less precisely and the tests here do not have the power to pick up small differences in expected return. The monotonic relation is still observed, however, when we consider the full 1965 to 1997 sample period.

\section{B. Seasonality}

\footnotetext{
${ }^{6}$ The $t$-statistic now is 4.61 compared with that of 3.07 reported by Jegadeesh and Titman (1993). The magnitude of momentum profits here is similar to that in Jegadeesh and Titman (1993) although the variability is now smaller because of the exclusion of stocks priced below $\$ 5$.
} 
Jegadeesh and Titman (1993) find a striking seasonality in momentum profits. They document that the winners outperform losers in all months except January but the losers significantly outperform the winners in January. This seasonality could potentially be a statistical fluke; January is one of twelve calendar months and it is possible that in any one calendar month momentum profits are negative. Here again, we can examine the out-of-sample performance of the strategy in January to examine whether this seasonality is real or whether it was the result of looking too closely at the data.

Table 2 reports the momentum profits in January and non-January. The results indicate that the losers outperformed the winners by an impressive $2.92 \%$ on average in January in the period 1965-1989. ${ }^{7}$ Losers again outperform winners in January in the nineties, but now the return difference is $1.21 \%$. While this difference is not statistically different from zero, it is significantly smaller than the momentum profits outside January. Also, the momentum profit was positive in only two of the eight Januarys in the 1990 to 1997 sample period. The momentum strategy earns about $1.47 \%$ outside January in the original sample period compared with that of $1.20 \%$ in the 1990 to 1997 sample period.

\section{Portfolio characteristics and abnormal returns}

This subsection examines the characteristics of the momentum portfolios and the risk adjusted momentum portfolio returns. Table 3 presents the characteristics of the momentum portfolios. The winners are on average larger than the losers since by design winners are stocks whose capitalizations have recently increased and losers are stocks whose capitalizations have recently declined. The average market capitalization decile rank for winners is 5.25 compared with a decile rank of 6.59 for losers. ${ }^{8}$ Both winners and losers tend to be smaller firms than average because smaller firms have more volatile returns and are thus more likely to be in the extreme return sorted portfolios.

Table 3 also presents the sensitivities of these portfolios to the three Fama-French factors. The market factor sensitivity in the Fama-French regression is 1.15 for the winners while it is marginally higher at 1.21 for the losers. The size factor (Fama-French SMB factor) sensitivity is .77 for the winners which is also less than the corresponding sensitivity of 1.06 for the losers. The

\footnotetext{
${ }^{7}$ The average momentum profit is $-6.49 \%$ in January when stocks priced below $\$ 5$ are included in the sample, which corresponds to the finding in Jegadeesh and Titman (1993) which included the lower priced stocks.

${ }^{8}$ Size decile rank of 1 is large firms and size decile rank of 10 is small firms.
} 
smaller size factor sensitivity for the winners is consistent with our earlier result that the winners on average tend to be larger firms than the losers. The losers also exhibit greater sensitivity (.24) to the distress factor (Fama-French HML factor) than do the winners (.05). This is because losers had recently experienced stock price declines leading to higher book-to-market ratios. The general picture presented by the results in Table 3 is that the winners are on average exposed to less risk with respect to the Fama-French factors.

Table 4 reports the alphas of the various momentum portfolios calculated with both the CAPM and the Fama-French three-factor model. The CAPM alphas of the momentum strategy are about the same as the raw return difference since both winners and losers have about the same betas. The Fama-French alpha for the winner minus loser portfolio is $1.29 \%$, which is larger that the corresponding raw return difference of $1.09 \%$. This difference is due to the larger sensitivity of the losers to the Fama-French factors, as reported in Table $3 .^{9}$

\section{Post-Holding Period Returns of Momentum Portfolios}

As discussed in Jegadeesh and Titman (1993), the observed momentum profits can be consistent with either underreaction or a delayed overreaction that can be attributed to what DeLong, Shleifer, Summers and Waldmann (1990) called positive feedback trading. In this section, we will examine the post-holding period returns of the stocks that comprise the momentum portfolio in more detail in an attempt to reexamine earlier evidence of delayed overreaction. Our analysis of the post-holding returns is motivated in part by recent behavioral papers that present models that include delayed overreaction. As we mentioned earlier, the postholding return evidence also addresses the issues previously raised by Conrad and Kaul (1998).

\section{A. Behavioral Models}

The null hypothesis of our post-holding period tests is that the momentum profits arise because investors underreact to information which is eventually fully incorporated into stock prices. Barberis, Shleifer and Vishny (1998) discuss how a "conservatism bias" might lead investors to underreact to information in a way that is consistent with our null hypothesis. The conservatism bias, identified in experiments by Edwards (1968), suggests that individuals underweight new information in updating their priors. If investors act in this way, prices will tend

\footnotetext{
${ }^{9}$ The alphas in the 1965 to 1989 and 1990 to 1997 subperiods are similar to those reported in Table 4.
} 
to slowly adjust to information, but once the information is fully incorporated in prices there is no further predictability in stock returns. This interpretation suggests that the post-holding period returns will be zero.

The recent behavioral literature is motivated in part by a body of evidence that suggests that the post-holding period returns may in fact be negative. For example, Jegadeesh and Titman (1993) present relatively weak evidence that the post-holding period returns of their momentum portfolio is negative, and DeBondt and Thaler (1985) provide stronger evidence of longer-term overreaction. In addition, the earlier mentioned evidence of the predictability of book to market ratios is consistent with the existence of overreaction. ${ }^{10}$

To explain the long-term overreaction as well as the shorter-term momentum Barberis, et. al. present a model that combines conservatism bias with what Tversky and Kahneman (1974) refer to as a "representative heuristic" which is the tendency of individuals to identify "an uncertain event, or a sample, by the degree to which it is similar to the parent population." In the context of stock prices, Barberis et al. argue that the representative heuristic may lead investors to mistakenly conclude that firms realizing extraordinary earnings growths will continue to experience extraordinary growth in the future. They argue that although the conservatism bias in isolation leads to underreaction, however, this behavioral tendency in conjunction with the representative bias can lead to long horizon negative returns for the momentum portfolios.

Daniel, Hirshleifer and Subramanyam (1998) and Hong and Stein (1998) propose alternative models that are also consistent with short-term momentum and long-term reversals. Daniel, et. al. argue that informed traders suffer from a "self-attribution" bias. In their model, investors observe positive signals about a set of stocks, some of which perform well after the signal is received. Because of their cognitive biases, the informed traders attribute the performance of ex-post winners to their stock selection skills and that of the ex-post losers to bad luck. As a result, these investors become overconfident about their ability to pick winners and thereby overestimate the precision of their positive signals for these stocks. Based on their increased confidence in their positive signals, they push up the prices of the winners above their fundamental values. The delayed overreaction in this model leads to momentum profits that are eventually reversed.

Hong and Stein (1998) follow a different route, which also leads to the prediction of short horizon momentum and long horizon return reversals. The Hong and Stein model does not

\footnotetext{
${ }^{10}$ See also Lakonishok, Shleifer and Vishny (1994).
} 
directly appeal to any behavioral biases on the part of investors but considers two groups of investors who trade based on different sets of information. The informed investors or the "news watchers" in their model obtain signals about future cash flows but ignore information in the past history of prices. The other investors trade based on a limited history of prices and, in addition, do not observe fundamental information. The information obtained by the informed investors are transmitted with a delay and hence are only partially incorporated in the prices when first revealed to the market. This part of the model contributes to underreaction, resulting in momentum profits. The technical traders extrapolate based on past prices and tend to push prices of past winners above their fundamental values. Return reversals obtain when prices eventually revert to their fundamentals. Both groups of investors in this model act rationally in updating their expectations conditional on their information sets but the return predictability occur due to the fact that each group uses only partial information in updating its expectation.

\section{B. The Conrad and Kaul (CK) Hypothesis}

Conrad and Kaul start with the hypothesis that stock prices follow random walks with drifts, and the unconditional drifts vary across stocks. The Conrad and Kaul hypothesis proposes that the differences in unconditional drifts across stocks explain momentum profits. Since any predictability under the CK hypothesis is due to differences in unconditional drifts across stocks and not due to the random component of price changes in any particular period, the profits from a momentum strategy should be the same in any post-ranking period under this hypothesis. In other words, this hypothesis predicts that the stocks on the long side of the momentum portfolio should continue to outperform stocks on the short side by the same magnitude in any post-ranking period.

\section{The Post-Holding Period Evidence}

Figure 1 summarizes the underreaction, the overreaction and price correction and the $\mathrm{CK}$ hypotheses. While all three hypotheses imply momentum profits in the holding period, the post holding period performance of the momentum portfolios differ sharply under the three hypotheses as discussed above.

To test these competing hypotheses we examine the returns of the momentum portfolio following the initial formation date. The theoretical models do not offer any guidance regarding the length of the post-holding period over which return reversals due to price corrections are 
expected to occur. Jegadeesh and Titman (1993) examine momentum portfolio returns up to three year after portfolio formation with the idea that even if markets are not fully efficient the effect of any information will likely be impounded in prices within this time frame. Recent studies related to initial public offerings and seasoned equity offerings, however, find evidence of underperformance even five years after the events. ${ }^{11}$ Therefore we extend the post-holding period to five years in this study.

Figure 2 presents the cumulative momentum profits over a 60 -month post formation period. Over the 1965 to 1997 sample period, the results reveal a dramatic reversal of returns in the second through fifth years. Cumulative momentum profit increases monotonically until it reaches $11 \%$ at the end of Month 12. From Month 13 to Month 60 the momentum profits are on average negative. By the end of Month 60 the cumulative momentum profit declines to $.79 \%$. In other words, virtually all of the momentum profits in the first 12 months is reversed over the following four years.

At this point it appears that the CK hypothesis is untenable. If momentum profits were entirely due to differences in unconditional risk between the winner and loser portfolios one would expect the average return of roughly $1 \%$ per month observed in the first six months of the holding period to be observed indefinitely. Under this hypothesis therefore the momentum profit at the end of Month 60 should be $60 \%$ ! Clearly, this hypothesis is not supported by the data.

Table 5 presents further details on the momentum portfolio in the first five years after portfolio formation. The average profit in the first 12 months of the holding period is $.93 \%$ per month, the average profit is $-.14 \%$ per month in the second year and $-.10 \%$ in the third year. Momentum profits continue to be negative in the fourth and fifth years after portfolio formation at $-.29 \%$ per month and $-.39 \%$ per month. ${ }^{12}$ These results are qualitatively consistent with the behavioral models, which predict that the momentum profits will eventually reverse. ${ }^{13}$ The return reversal, however, appears to take place very gradually and merit further examination.

As Table 2 reports, the loser portfolios have larger sensitivities to the Fama and French size and book-to-market factors. The negative returns observed in the second and third years after portfolio formation may therefore represent compensation for factor risks. Furthermore, the

\footnotetext{
${ }^{11}$ See Loughran and Ritter (1995) and Spiess and Affleck-Graves (1995) among others.

${ }^{12}$ Momentum profits are negative in four of the five years from Year 6 thorough Year 10 but they are not reliably different from zero.
} 
Fama-French factors exhibit a January seasonal. In our sample period, the Fama-French size factor has an average return of $2.39 \%$ in January compared with $.03 \%$ outside January, while the book-to-market factor has an average return of $2.47 \%$ in January and $.25 \%$ outside January. If the negative returns for the momentum portfolios are due to their exposures to the Fama-French factors then we would expect that a large portion of these negative returns will also be concentrated in January.

Table 5 (Panel B) presents the momentum profits in January and outside January over the post-formation holding periods. The average momentum profit in January is $-2.20 \%$ in the first year and $-2.53 \%$ in the second year and becomes less negative, about $-.90 \%$, in years 4 and 5 . The January raw returns are always reliably different from zero. The momentum profits outside January, however are marginally positive in the second and third years but are reliably negative in the fourth and fifth year.

Panel $\mathrm{C}$ of Table 5 presents the Fama-French three-factor alphas for the momentum portfolios. The alphas are significantly negative only in years 4 and 5 . The alphas in January are typically marginally negative and closer to zero than the raw returns. Therefore, at least part of the mean reversion over the long horizon appears attributable to differences in the factor sensitivities of the winner and loser portfolios.

To investigate the robustness of long horizon return reversals we examine the performance of momentum portfolios in two separate time periods, the 1965 to 1980 and 1981 to 1997 subperiods. In addition to being roughly the half-way point, 1981 represents somewhat of a break point for the Fama and French factor returns. The Fama-French SMB and HML factors have higher returns in the pre-1981 period (the monthly returns of the HML and SMB factors average $.49 \%$ and $.53 \%$ respectively, see Table $5 \mathrm{~A}$ ) than in the post- 1981 period (the monthly returns of the HML and SMB factors average $.38 \%$ and $-.10 \%$ respectively).

The momentum strategy is significantly profitable, and quite similar in both subperiods, in the first 12 months following the formation date. The returns, however, are quite different in the two subperiods in the subsequent months. In the 1965 to 1981 subperiod, the cumulative momentum profit declines from $11.28 \%$ at the end of Month 12 to 5.49\% at the end of Month 36 and then declines further to $-5.81 \%$ at the end of Month 60 . In fact, the momentum profits are negative in

\footnotetext{
${ }^{13}$ The F-statistic under the hypothesis that annual returns in years 2 through 5 are jointly equal to zero is 6.86 , which indicates strong rejection of the null hypothesis.
} 
each event month after Month 12 in this subperiod. In the 1982 to 1997 subperiod the cumulative profits increase from $10.71 \%$, at the end of month 12 , to $11.69 \%$ at the end of Month 36 but then declines to $7.59 \%$ at the end of Month 60 . The only significant negative returns, in the later subperiod, is in the fifth year after portfolio formation.

The findings in this section are supportive of behavioral models that suggest that momentum returns should later be reversed, but this interpretation should be tempered with caution. The first concern is that a large part of the return reversal takes place in the fourth and fifth year after portfolio formation while there is much less evidence of return reversals in the second and third years. ${ }^{14}$ In addition, a significant part of the return reversal takes place in the months of January while the momentum profits in the holding period are entirely a non-January phenomenon. Finally, although the phenomenon of momentum profits is robust both in sign and magnitude across subperiods, evidence of return reversals are much weaker in the second time period.

\section{Cross-Sectional Dispersion in Expected Returns and Momentum Profits}

\section{A. Weighted Relative Strength Strategies}

The contrast between our conclusions in the last section and the conclusions in Conrad and Kaul (1998) is particularly striking. Recall, that Conrad and Kaul argue that the magnitude of the momentum profits could be explained by the cross-sectional variation in expected returns and does not require time-series variation in expected returns. They reach this conclusion based on indirect empirical tests and provide further support for their hypothesis with a number of simulations. This section reconciles the divergence between our findings and the conclusions in Conrad and Kaul. Specifically, our analysis indicates that their empirical tests overestimate the contribution of cross-sectional differences in mean returns to momentum profits. Indeed, the empirical estimates we present here indicate that the contribution of differences in expected returns to momentum profits is negligible. We also demonstrate how a simple flaw in their simulations led Conrad and Kaul astray.

\footnotetext{
${ }^{14}$ While the evidence that the information available during the ranking period seems to trickle very slowly into prices appears quite puzzling, we need to point out that a similar pattern of long horizon returns has been documented in the case of seasoned equity offerings as well. Specifically, firms that issue seasoned equity perform similar to their benchmarks in the year following the offerings but underperform their benchmarks significantly in each of the next four years.
} 
We start with the simple decomposition that was examined originally in Lo and MacKinlay (1990) and used in the Conrad and Kaul (1998) analysis. This decomposition is derived from a momentum strategy that buys stocks in proportion to their returns over the previous ranking period. Specifically, under this strategy, which we label the weighted relative strength strategy (WRSS), each stock is assigned a weight at time $t$ given by:

$$
w_{i, t}=\frac{1}{N}\left(r_{i, t-1}-\bar{r}_{t-1}\right)
$$

where $N$ is the number of stocks in the sample, $r_{i, t-l}$ is the return of stock $i$ during the ranking period $t-1$ and $\bar{r}_{t-1}$ is the average return across all stocks in the sample at time $t-1$. Under this weighting scheme, the average weight across all stocks is zero but the sum of the weights for the long or short positions vary month to month depending on past return dispersions and in general is different from one. Since in our empirical work we focus on six-month momentum strategies the length of each period can be thought of as six months.

The profit from this strategy, denoted as $\pi_{\mathrm{t}}$, can be expressed as:

$$
\pi_{t}=\frac{1}{N} \sum_{i=1}^{N} r_{i, t}\left(r_{i, t-1}-\bar{r}_{t-1}\right) .
$$

The difference between the momentum strategy described in the previous sections and the above strategy is that the WRSS assigns relatively large weights to the extreme winners and losers and smaller but non-zero weights to stocks that are not in the extreme deciles. In practice, investment strategies implemented to exploit momentum are likely be closer to our earlier decile portfolio strategy than to the WRSS, but the latter strategy is more convenient for analytically examining the different sources of momentum profits.

Table 6 reports the profits to the momentum strategy over the sample period 1965 to 1997. The average profit is .00379 , which is reliably different from zero. The WRSS produces returns that are highly correlated (about .95) with the momentum strategies with the decile portfolio strategy examined in the previous section.

To decompose the WRSS profit, the realized return for stock $i$ is expressed as:

$$
r_{i, t}=\mu_{i}+u_{i, t},
$$


where $\mu_{i}$ is the unconditional expected return of stock $i$ and $u_{i, t}$ is the unexpected return at time $t$. The momentum profits in (1) can now be decomposed into components based on expected and unexpected components of returns as follows:

$$
\pi_{t}=\sigma_{\mu}^{2}+\frac{1}{N} \sum_{i=1}^{N} \operatorname{cov}\left(u_{i, t}, \mu_{i, t-1}\right),
$$

where $\sigma_{\mu}^{2}$ is the cross-sectional variance of expected returns. This expression indicates that any variation in expected returns will contribute positively to momentum profits. To see the intuition, note that the momentum strategies sort stocks based on realized returns. If a large part of realized returns is due to expected returns then past winners will tend to be stocks with higher than average expected returns and past losers will tend be stocks with lower than average expected returns. Given this, past winners tend to be stocks with high expected returns which will on average continue to earn higher than average returns in the future and the reverse will be true for the losers.

Most previous research emphasized the importance of the second term in the decomposition, the serial correlation term. However, Conrad and Kaul (1998) argue that most of the momentum returns can be explained by the first term in the decomposition, the cross-sectional variance in expected returns $\left(\sigma_{\mu}^{2}\right)$. In other words, they claim that the momentum profits can be explained without resorting to behavioral stories about investors under or over-reacting to information.

To estimate $\sigma_{\mu}^{2}$, Conrad and Kaul use the average realized return of each stock as their measure of the stock's expected return. Formally, this estimator of expected returns is,

$$
\widehat{\mu}_{i}=\frac{1}{T_{i}} \sum_{t=1}^{T_{i}} r_{i, t},
$$

where $T_{i}$ is the number of observations available for stock $i$. Table 6 reports the cross-sectional variance of $\bar{\mu}_{i}$ which is over $134 \%$ of the WRSS profits. This point estimate suggests that perhaps the entire momentum profit is attributable to cross-sectional differences in expected returns.

The variance of sample mean returns, however, considerably overestimates the dispersion in true expected returns. To see this, let

$$
\hat{\mu}_{i}=\mu_{i}+\varepsilon_{i}
$$


where $\varepsilon_{i}$ represents estimation error. Since $\widehat{\mu}_{i}$ is an unbiased estimator of expected returns, $E\left(\varepsilon_{i}\right)=0$. However, since $\sigma_{\tilde{\mu}_{i}}^{2}=\sigma_{\mu_{i}}^{2}+\sigma_{\varepsilon_{i}}^{2}$, the variance of the estimated expected returns overestimates the cross-sectional variance of true expected returns. ${ }^{15}$ The magnitude of this overestimation is exacerbated by the fact that, following Conrad and Kaul, we have used all stocks in the sample period for the calculation of expected returns, regardless of the length of their return history. In fact, some of the stocks in our sample have return series that are less than seven months long and hence their expected return estimates based on estimator (3) are notoriously imprecise.

To evaluate the extent to which the measurement error in sample mean could potentially bias the estimates of dispersion in true expected returns, Figure 3 plots the distribution of sample mean returns. Estimated expected returns are negative for nearly 20 percent of the stocks in the sample. For some stocks the sample mean returns are even less than $-80 \%$, and on the positive side, some stocks had experienced average returns in excess of $100 \%$. It is unlikely that these sample average returns capture the stocks' true ex-ante expected returns. These measurement errors, therefore, bias upwards the CK estimate of the extent to which cross-sectional differences in returns contribute to momentum profits.

\section{B. Direct Tests of Risk Hypothesis}

Up to this point we have followed the Conrad and Kaul approach to examine whether crosssectional differences in expected returns can potentially explain the momentum profits. This approach, at best, is indirect and fraught with difficulties since it is hard to obtain precise estimates of expected returns. Fortunately, more direct alternatives are available to examine this hypothesis. For example, as we earlier showed, Table 4 presents momentum profits that were adjusted for risk with the CAPM (one factor model) and the Fama-French three factor models. These methods, however, can be criticized because there is no guarantee that they account for all risk factors. However, there is no need to use a specific asset pricing model to obtain unbiased estimates of expected returns if we are willing to impose the assumption made by Conrad and

\footnotetext{
${ }^{15}$ Conrad and Kaul use overlapping six month returns to estimate the expected returns for each stocks and argue that since they "use overlapping holding period returns at monthly frequency" the impact of measurement errors is substantially reduced. However, mean return depend on the length of the sample period and the beginning and end of period stock prices and the frequency with which prices are sampled does not alter the estimates or the precision of the estimates (see Merton (1980)).
} 
Kaul that expected returns are constant over time. In this case, we can use sample average returns, as described in (3), as an unbiased estimate of expected returns. As we will see below, our application here only requires that the expected return estimator be unbiased and unlike the CK approach we do not require that the variance of sample mean returns is an unbiased estimator of the variance of true expected returns.

We compute sample average returns for each firm over three different sample periods. The first measure is the ex-ante sample means computed over the pre-ranking period. Specifically, the ex-ante sample mean for the ranking period ending in month $t$ :

$$
\widehat{\mu}_{i, t}(1)=\frac{1}{\left(t-6-T_{i, p r e}+1\right)} \sum_{j=T_{i, p r e}}^{t-6} r_{i, j},
$$

where $T_{i, p r e}$ is the first date on or after January 1963 for which returns data for firm $i$ can be obtained from the CRSP data base. The ex-ante sample period excludes the ranking period since by construction the returns are low for losers and high for winners in this period.

The advantage of using the ex-ante ranking period returns is that this estimate is available to the investor at the time of portfolio formation. However, since losers experienced drops in their equity values and winners experienced gains, it is likely that their financial leverage changed during the ranking period and hence resulted in changes in their risk exposures. Since ex-ante means do not account for the effect of the changes in risk, our second measure obtains an estimate of expected returns using sample means in the post-holding periods. Specifically, for each stock we compute the post-holding period sample mean as follows for ranking periods ending in month $t:$

$$
\widehat{\mu}_{i, t}(2)=\frac{1}{\left(T_{i, p o s t}-(t+13)+1\right)} \sum_{j=t+13}^{T_{i, p o s s}} r_{i, j}
$$

where $T_{i, p o s t}$ is the last month for which return data for firm $i$ is available. Since we are trying to explain the returns in the holding period, we exclude the 12-month period following the ranking period to calculate these averages. ${ }^{16}$

Our final estimate of expected returns is computed over both pre-ranking and post-holding periods. Specifically,

\footnotetext{
${ }^{16}$ The sample period ends December 1996 when we use the estimator $\widehat{\mu}_{i, t}(2)$.
} 


$$
\hat{\mu}_{i, t}(3)=\frac{1}{\left(T_{i, p o s t}-(t+13)+1\right)+\left(t-6-T_{i, p r e}+1\right)}\left(\sum_{j=T_{r, p r e}}^{t-6} r_{i, j}+\sum_{j=t+13}^{T_{i, p s s t}} r_{i, j}\right)
$$

Using these estimators, we compute the abnormal returns $r_{i, t}^{a b}(k)$ for each stock during the holding period as:

$$
r_{i, l}^{a b}(k)=r_{i, t}-\hat{\mu}_{i, l}(k), k=1,2,3 .
$$

Table 6 presents the abnormal momentum profits. The average abnormal return after adjusting for pre-ranking period mean returns is $1.30 \%$ per month. The momentum profits are now marginally larger than the raw profits reported in Table 1 . The average abnormal returns after adjusting for post-holding period mean returns is $1.08 \%$ per month and after adjusting for the combined sample period mean return is $1.28 \%$ per month. ${ }^{17}$ The results here indicate that the contribution of cross-sectional variation in mean returns to momentum profits is marginal at best.

\section{The Simulation Puzzle}

One puzzle that still remains is the simulation evidence presented by Conrad and Kaul, which leads them to conclude that the "main determinant of the profits of return-based trading strategies is the cross-sectional variation in mean returns." The CK simulation results are indeed in direct conflict to the empirical evidence provided in this paper. In this section we describe the CK simulation procedure and point out a bias in their procedure which is responsible for the findings they generate.

The Conrad and Kaul bootstrap experiment works as follows: They first scramble the monthly returns for each stock by randomly drawing a return for each month, with replacement, from the observed distribution of the stock's returns. This scrambling process should eliminate any serial correlation in the return series. Based on these scrambled returns, the profits of the momentum strategy are calculated for 500 replications. Table 8 reports the simulated momentum profits generated from this procedure along with the actual profits of the strategy for comparison.

\footnotetext{
${ }^{17}$ Note that the profits after adjusting for combined period mean returns in not the average of the momentum profits after adjusting for pre-ranking period and post-holding period mean returns since different stocks enter the winner and loser portfolios at different points in time.
} 
Consistent with the results reported by Conrad and Kaul, the simulated profits are similar to the profits observed with the actual data. ${ }^{18}$

Because they generate the same momentum returns from the scrambled return series, the Conrad and Kaul simulations suggest that the momentum profits arise because of the crosssectional dispersion rather than their time-series pattern. However, there is a critical flaw in the design of this experiment. By drawing returns, with replacement, a bias is introduced into the simulation that arises because the same observation for any stock can be drawn in both ranking and holding periods. This bias can be easily illustrated with a simple example where one stock realizes a particular high return in one month (say one thousand percent). In any particular month that this return is drawn, because of its extreme return, the stock will fall in the winner portfolio. If this particular observation is drawn in an adjacent 6 month period, which is not unlikely given the length of the return time series, the simulation will spuriously show high returns in the holding period. This small sample bias is formally derived in the Appendix.

To overcome this source of bias we repeat the same bootstrap experiment, but this time without replacement. As we show in the Appendix, by sampling without replacement we avoid the small sample bias that arises in samples drawn with replacement. With this simulation the average momentum profit is .00002 , which is $.53 \%$ of the profits observed in the actual date (see Table 8). The simulation profit is also not reliably different from zero, suggesting that the positive returns generated in the previous simulation was generated because the samples were drawn with replacement. These simulations indicate that only a very small portion of the momentum returns are generated from the cross-sectional variation in expected returns. ${ }^{19}$

\footnotetext{
${ }^{18}$ The $t$-statistics, however, are much larger with the simulations since scrambling the return data for each stock individually destroys the cross-sectional correlation in stock returns and hence the profits to the simulated strategy has a much smaller variance.

${ }^{19}$ Conrad and Kaul also carry out two other simulation experiments to further augment their claims. In these simulations they set the "expected" returns for each stock equal to their sample average returns, the distribution of which is given in Figure 3. As can be seen from this figure, some stocks earn average returns of less that $-80 \%$ while other stocks earn average returns in excess of $100 \%$. There is clearly substantially more cross-sectional variation in these average returns than one would expect to find in expected returns. Hence, estimates of the components of momentum returns that use average returns as proxies for expected returns substantially overestimate the component of profits that are due to the cross-sectional variation in expected returns and underestimate the component due to serial correlation.
} 


\section{Conclusions}

This paper evaluates various explanations for the momentum profits documented previously in Jegadeesh and Titman (1993). We first document that the momentum profits in the eight years subsequent to the Jegadeesh and Titman (1993) sample are remarkably similar to the profits found in the earlier time period. This evidence provides some assurance that the momentum profits are not entirely due to data snooping biases.

To learn more about the source of momentum profits, we examined the returns of the momentum portfolios in the post-holding period. By examining the post-holding period performance, we are able to address issues that were raised recently by Conrad and Kaul (1998), Barberis et. al. (1998), Daniel et. al. (1998) and Hong and Stein (1998). Conrad and Kaul argue that there is no discernable time-series variation in returns and that momentum returns arise because of cross-sectional variation in returns. This argument implies that the post-holding period returns of the momentum portfolio should be significantly positive. In contrast, the later three papers present behavioral models that suggest that the post-holding period returns of the momentum portfolio should be negative.

Our evidence suggests that the abnormal performance of the momentum portfolio in the 13 to 60 months following the formation month is negative. This evidence supports the behavioral models, which argue that momentum profits are generated by delayed overreaction. We believe, however, that this evidence should be viewed with some caution. We are somewhat troubled by the fact that there is no evidence of a return reversal until 4 years after the formation date. In addition, we only observe a partial and only marginally significant return reversal in the later time period. However, the momentum profits in the two time periods are essentially equal.

Although the behavioral models are difficult to evaluate, our evidence is clearly inconsistent with the Conrad and Kaul (1998) hypothesis that momentum profits arise because of crosssectional differences in expected returns rather than time-series predictability. Since we reach very different conclusions after examining essentially the same data as Conrad and Kaul (1998), we have carefully examined their procedures to better understand why our conclusions are so different. We were particularly concerned about their results indicating that momentum profits can be generated on simulated data that is created by randomly scrambling the sequence of each stock's returns. Since this scrambling process should eliminate the serial correlation that exists in 
actual returns data, the positive momentum profits they generated from these simulated returns is somewhat surprising.

Our analysis indicates that the simulated momentum profits generated in the Conrad and Kaul study arise because their experimental design has a small sample bias. Their procedure samples from each stock's realized return with replacement, which allows extreme observations to be drawn in two adjacent 6 month periods biasing momentum profits upwards. When we redo their simulations by drawing samples without replacement, the momentum profits observed in their simulations disappear. What this means is that the momentum profits observed in the actual data is generated because of the time-series properties of stock returns, not because of the crosssectional variation in returns. 


\section{References}

Banz, R., 1981, "The relation between return and market value of common stocks," Journal of Financial Economics 9, 3-18.

Barberis, N., A. Shleifer, and R. Vishny, 1998, “A model of investor sentiment," Journal of Financial Economics 49(3), 307-343.

Chan, L.K., N. Jegadeesh and J. Lakonishok, 1996, "Momentum Strategies," Journal of Finance 51, 1681-1713.

Conrad, J., and G. Kaul, 1993, “Long-term overreaction or biases in computed returns?', Journal of Finance 48, 39-63.

Conrad, J., and G. Kaul, 1998, “An anatomy of trading strategies," Review of Financial Studies $11,489-519$.

Daniel, K., D. Hirshleifer, and A. Subrahmanyam, 1998, "Investor Psychology and security market under-and overreactions," Journal of Finance 53, 1839-1886.

Daniel, K. D. and S. Titman, 1997, "Evidence on the characteristics of cross-sectional variation in stock returns," Journal of Finance 52, 1-33.

DeBondt, W.F.M and R. H. Thaler, 1985, 'Does the stock market overreact?'” Jourmal of Finance 40, 793-805.

DeLong, J.B., A. Shleifer, L.H. Summers, Waldmann, R.J., 1990, "Positive feedback investment strategies and destabilizing rational speculation, Journal of Finance 45, 379-395.

Edwards, W., 1962, 'Conservatism in human information processing,' In: Kleimutz, B. (ed.), Representation of Human Judgement, John Wiley and Sons, New York, 17-52

Fama, E., and K. French, 1993, "Common risk factors in the returns on stocks and bonds," Journal of Financial Economics 33, 3-56.

Fama, E., and K. French, 1996, "Multifactor explanations of asset pricing anomalies," Journal of Financial Economics 51, 55-84.

Grinblatt, M. and T. Moskowitz, 1999, "Does industry explain momentum,” Journal of Finance (forthcoming).

Grundy, B. D. and S. J. Martin, 1998, “Understanding the nature of risks and the sources of rewards to momentum investing," working paper, Wharton School, U. Penn

Haugen, R. A., 1999, The New Finance, Prentice Hall, Upper Saddle River, NJ. 
Hong, H., and J. Stein, 1998, "A unified theory of underreaction, momentum trading and overreaction in asset markets," Working paper, MIT Sloan School of Management.

Keim, D. B., 1983, ' Size-related anomalies and stock return seasonality: Further empirical evidence,' Journal of Financial Economics 12, 13-32.

Jegadeesh, N., and S. Titman, 1993, "Returns to buying winners and selling losers: Implications for stock market efficiency," Journal of Finance 48, 65-91.

Lakonishok, J., A. Shleifer, and R. W. Vishny, 1994, Contrarian investment, extrapolation and risk, Journal of Finance 49, 1541-78.

Lo, A., and A. C. MacKinlay, 1990, "When are contrarian profits due to stock marketoverreaction?," Review of Financial Studies 3, 175-208.

Loughran, T., and J. R. Ritter, 1995, The new issues puzzle, Journal of Finance 50, 23-51.

Merton, R. C., 1980, "On estimating the expected return on the market: An exploratory investigation,' Journal of Financial and Quantitative Analysis 7, 323-361.

Tversky, A. and D. Kahneman, 1974, “Judgement under uncertainty: Heuristics and Biases," Science 185, 1124-1131.

Rowenhorst, K.G., 1998, "International momentum strategies,” Journal of Finance 53, 267-284.

Spiess, D. Katherine, and John Affleck-Graves, 1995, Underperformance in long-run stock returns following seasoned equity offerings, Journal of Financial Economics 38, 243-267. 
Table 1

Momentum Portfolio Returns

\begin{tabular}{|c|c|c|c|}
\hline & $1965-89$ & $1990-1997$ & $1965-1997$ \\
\hline P1 (Past Winners) & 1.70 & 1.55 & 1.67 \\
\hline $\mathrm{P} 2$ & 1.50 & 1.25 & 1.44 \\
\hline$\overline{\mathrm{P} 3}$ & 1.40 & 1.18 & 1.35 \\
\hline $\mathrm{P} 4$ & 1.32 & 1.17 & 1.29 \\
\hline $\mathrm{P5}$ & 1.31 & 1.13 & 1.27 \\
\hline P6 & 1.25 & 1.11 & 1.22 \\
\hline P7 & 1.22 & 1.19 & 1.21 \\
\hline P8 & 1.16 & 1.11 & 1.15 \\
\hline P9 & 1.07 & 1.13 & 1.08 \\
\hline P10 (Past Losers) & 0.59 & 0.54 & 0.58 \\
\hline $\mathrm{P} 1-\mathrm{P} 10$ & 111 & 1.01 & 109 \\
\hline$t$-statistic & 4.61 & 4.10 & 5.65 \\
\hline
\end{tabular}

Note: This table reports the monthly returns for momentum portfolios formed with stocks traded on the NYSE/AMEX. All stocks priced less than $\$ 5$ at the beginning of the holding period are excluded from the sample. The momentum deciles are formed based on 6-month lagged returns and held for six months. P1 is the equal-weighted portfolio of ten percent of the stocks with the highest six-month lagged returns, $\mathrm{P} 2$ is the equal-weighted portfolio of the ten percent of the stocks with the next highest returns and so on. 
Table 2

Momentum portfolio Returns in January and outside January

\begin{tabular}{|l|l|l|l|l|l|l|}
\hline & & P1 & P10 & P1-P10 & $t$-statistic & $\begin{array}{c}\text { Percent } \\
\text { Positive }\end{array}$ \\
\hline \multirow{5}{*}{$1965-1989$} & Jan & 4.68 & 7.60 & -2.92 & -2.45 & 28.00 \\
\cline { 2 - 7 } & Feb-Dec & 1.43 & -0.04 & 1.47 & 6.48 & 70.91 \\
\cline { 2 - 7 } & All & 1.70 & 0.59 & 1.11 & 4.61 & 67.33 \\
\hline \multirow{1}{*}{$1990-1997$} & Jan & 2.08 & 3.29 & -1.21 & -1.28 & 25.00 \\
\cline { 2 - 7 } & Feb-Dec & 1.50 & 0.30 & 1.20 & 4.94 & 71.59 \\
\cline { 2 - 7 } & All & 1.55 & 0.54 & 1.01 & 4.10 & 67.71 \\
\hline $1965-1997$ & Jan & 4.05 & 6.56 & -2.51 & -2.68 & 27.27 \\
\cline { 2 - 7 } & Feb-Dec & 1.45 & 0.04 & 1.41 & 7.73 & 71.07 \\
\cline { 2 - 7 } & All & 1.67 & 0.58 & 1.09 & 5.65 & 67.42 \\
\hline
\end{tabular}

Note: This table reports the monthly returns for momentum portfolios formed with stocks traded on the NYSE/AMEX. All stocks priced less than $\$ 5$ at the beginning of the holding period are excluded from the sample. The momentum deciles are formed based on 6-month lagged returns and held for six months. $\mathrm{Pl}$ is the equal-weighted portfolio of ten percent of the stocks with the highest six-month lagged returns (past winners) and P10 is the equal-weighted portfolio of the ten percent of the stocks with the lowest returns. 
Table 3

\section{Portfolio Characteristics}

\begin{tabular}{|l|l|l|l|l|}
\hline \multirow{2}{*}{} & \multirow{2}{*}{\begin{tabular}{l} 
Average size decile rank \\
\cline { 3 - 5 }
\end{tabular}} & & \multicolumn{3}{|c|}{ FF factor sensitivities } \\
\cline { 3 - 5 } & & Market & SMB & HML \\
\hline P1 & 5.25 & 1.15 & 0.77 & 0.05 \\
\hline P2 & 4.33 & 1.08 & 0.57 & 0.18 \\
\hline P3 & 4.17 & 1.04 & 0.51 & 0.25 \\
\hline P4 & 4.17 & 1.02 & 0.49 & 0.27 \\
\hline P5 & 4.06 & 1.00 & 0.52 & 0.29 \\
\hline P6 & 4.25 & 1.01 & 0.54 & 0.30 \\
\hline P7 & 4.56 & 1.02 & 0.61 & 0.31 \\
\hline P8 & 4.68 & 1.03 & 0.67 & 0.30 \\
\hline P9 & 4.96 & 1.07 & 0.80 & 0.28 \\
\hline P10 & 6.59 & 1.21 & 1.06 & -0.29 \\
\hline P1-P10 & -1.34 & -0.06 & -0.29 & -0.19 \\
\hline
\end{tabular}

Note: This table reports the characteristics of momentum portfolios formed with stocks traded on the NYSE/AMEX. All stocks priced less than $\$ 5$ at the beginning of the holding period are excluded from the sample. The momentum deciles are formed based on 6-month lagged returns. P1 is the equal-weighted portfolio of ten percent of the stocks with the highest six-month lagged returns, $P 2$ is the equal-weighted portfolio of the ten percent of the stocks with the next highest retums and so on. Average size decile rank is the average rank of the market capitalization of equity of the stocks in each portfolio at the beginning of the holding period. FF factor sensitivities are the slope coefficients in the Fama-French three-factor model time-series regressions. "Market" is the market factor, "SMB" is the size factor and "HML' is the book-to-market factor. The sample period is January 1965 to December 1997. 


\section{Table 4}

\section{CAPM and Fama-French Alphas}

\begin{tabular}{|l|l|l|}
\hline & CAPM Alpha & FF Alpha \\
\hline P1 & 0.54 & 0.30 \\
\hline P2 & 0.37 & 0.12 \\
\hline P3 & 0.31 & 0.04 \\
\hline P4 & 0.26 & -0.02 \\
\hline P5 & 0.25 & -0.05 \\
\hline P6 & 0.19 & -0.11 \\
\hline P7 & 0.18 & -0.14 \\
\hline P8 & 0.11 & -0.23 \\
\hline P9 & 0.01 & -0.35 \\
\hline P10 & -0.57 & -0.99 \\
\hline P1-P10 & 1.11 & 1.29 \\
\hline$t$-statistic & 4.59 & 7.78 \\
\hline
\end{tabular}

Note: This table reports the characteristics of momentum portfolios formed with stocks traded on the NYSE/AMEX. All stocks priced less than $\$ 5$ at the beginning of the holding period are excluded from the sample. The momentum deciles are formed based on 6-month lagged returns. Pl is the equal-weighted portfolio of ten percent of the stocks with the highest six-month lagged returns, $\mathrm{P} 2$ is the equal-weighted portfolio of the ten percent of the stocks with the next highest returns and so on. This table reports the intercepts from the market model regression (CAPM Alpha) and Fama-French threefactor model regression. time-series regression (FF Alpha). The sample period is January 1965 to December 1997. 


\section{Table 5}

\section{Seasonality in Longer Horizons Momentum Profits and Fama and French Factors}

Panel A. Average Factors

\begin{tabular}{|l|l|l|l|}
\hline \multirow{2}{*}{$\begin{array}{l}\text { Calendar } \\
\text { Months }\end{array}$} & \multicolumn{3}{|c|}{ Fama-French Factors } \\
\cline { 2 - 4 } January & Market & SMB & HML \\
& 1.97 & 2.39 & 2.47 \\
& $(2.13)$ & $(3.73)$ & $(4.52)$ \\
\hline Feb-Dec & .36 & .03 & .25 \\
& $(1.59)$ & $(.19)$ & $(1.96)$ \\
\hline All & .49 & .22 & .43 \\
& $(2.22)$ & $(1.54)$ & $(3.37)$ \\
\hline
\end{tabular}

Panel A. Raw Returns

\begin{tabular}{|l|l|l|l|l|l|}
\hline \multirow{2}{*}{$\begin{array}{l}\text { Calendar } \\
\text { Months }\end{array}$} & \multicolumn{5}{|c|}{ Momentum Portfolio Returns (P1-P10) } \\
\cline { 2 - 6 } & Months 1 to & Months 13 to & $\begin{array}{l}\text { Months 25 to } \\
36\end{array}$ & $\begin{array}{l}\text { Months 37 to } \\
48\end{array}$ & $\begin{array}{l}\text { Months 49 to } \\
\end{array}$ \\
& 12 & 24 & -1.63 & -.90 & 60 \\
\hline January & -2.20 & -2.53 & $(-3.68)$ & $(-2.50)$ & -.91 \\
& $(-3.11)$ & $(-4.50)$ & .04 & -.24 & $(-2.13)$ \\
\hline Feb-Dec & 1.21 & .08 & $(.39)$ & $(-2.56)$ & -.34 \\
& $(8.48)$ & $(.03)$ & -.10 & -.29 & $(-3.43)$ \\
\hline All & .93 & -.14 & $(-1.11)$ & $(-2.51)$ & $(-3.10)$ \\
& $(6.12)$ & $(-1.34)$ & & & \\
\hline
\end{tabular}

Panel C. Fama-French three factor alphas

\begin{tabular}{|l|l|l|l|l|l|}
\hline \multirow{2}{*}{$\begin{array}{l}\text { Calendar } \\
\text { Months }\end{array}$} & \multicolumn{5}{|c|}{ Momentum Portfolio Alphas (P1-P10) } \\
\cline { 2 - 6 } & Months 1 to 12 & Months 13 to 24 & Months 25 to 36 & Months 37 to 48 & Months 49 to 60 \\
\hline January & -.68 & -.54 & -.25 & -.85 & -.25 \\
& $(-.74)$ & $(-.91)$ & $(-.47)$ & $(-1.64)$ & $(-.39)$ \\
\hline Feb-Dec & 1.23 & .14 & .10 & -.20 & -.32 \\
& $(8.53)$ & $(1.69)$ & $(1.18)$ & $(-2.49)$ & $(-3.65)$ \\
\hline All & 1.09 & .07 & .07 & -.22 & -.31 \\
& $(7.16)$ & $(.76)$ & $(.79)$ & $(-2.67)$ & $(-3.56)$ \\
\hline
\end{tabular}

Note: Panel A presents average Fama-French factors, Panel B presents monthly momentum profits one, two, three, four and five years after formation of momentum portfolios. See Table 1 for a description of portfolio construction. Panel A also presents the average monthly returns on the three Fama and French risk factors. "Market" is the market factor, "SMB" is the size factor and "HML" is the book-to-market factor. The sample period is January 1965 to December 1997

Panel $\mathrm{C}$ presents the intercepts from the Fama-French three factor regressions fitted over all months in the sample period and separately within and outside January. The $t$-statistics are reported in parentheses. 


\section{Table 5 A}

\section{Longer Horizons Momentum Profits and Fama and French Factors - Subperiod Results}

\begin{tabular}{|c|c|c|c|}
\hline \multicolumn{4}{|c|}{ A. Fama-French factors } \\
\hline & Market & SMB & HML \\
\hline $1965-1981$ & $\begin{array}{l}.15 \\
(.48) \\
\end{array}$ & $\begin{array}{l}.53 \\
(2.34)\end{array}$ & $\begin{array}{l}.49 \\
(2.61) \\
\end{array}$ \\
\hline $1982-1997$ & $\begin{array}{l}.84 \\
(2.81)\end{array}$ & $\begin{array}{l}-.10 \\
(-.57) \\
\end{array}$ & $\begin{array}{l}.38 \\
(2.13)\end{array}$ \\
\hline
\end{tabular}

\begin{tabular}{|l|l|l|l|l|l|}
\hline \multicolumn{5}{|l|}{ B. Momentum portfolio raw returns } \\
\hline & \multicolumn{5}{|c|}{ Holding Period } \\
\hline & Months 1 to 12 & Months13 to 24 & Months 25 to 36 & Months 37 to 48 & Months 49 to 60 \\
\hline $1965-1981$ & .94 & -.32 & -.21 & -.44 & -.56 \\
& $(3.78)$ & $(-1.94)$ & $(1.51)$ & $(-3.46)$ & $(-4.09)$ \\
\hline $1982-1997$ & .92 & .05 & .01 & -.14 & -.21 \\
& $(5.43)$ & $(.46)$ & $(.05)$ & $(-1.32)$ & $(-1.80)$ \\
\hline & C. Momentum portfolio Fama-French three factor alphas \\
\hline $1965-1981$ & 1.21 & -.01 & .03 & -.29 & -.38 \\
& $(4.91)$ & $(-.06)$ & $(.25)$ & $(-2.32)$ & $(2.87)$ \\
\hline $1982-1997$ & 1.01 & .16 & -13 & -.11 & -.29 \\
& $(5.67)$ & $(1.40)$ & $(1.11)$ & $(-1.08)$ & $(2.43)$ \\
\hline
\end{tabular}

Note: Panel A also presents the average monthly returns on the three Fama and French risk factors. "Market" is the market factor, "SMB" is the size factor and "HML" is the book-to-market factor. Panel B presents the average monthly momentum profits or the P1-P10 portfolio one, two, and three years after formation of momentum portfolios. See Table 1 for a description of portfolio construction. Panel C presents the intercepts from the FamaFrench three factor regressions fitted within each subperiod. The $t$-statistics are reported in parentheses. 


\section{Table 6}

\section{Weighted Relative Strength Strategy (WRSS) Profits (1965-1997)}

\begin{tabular}{|l|l|l|}
\hline & WRSS Profit & $\begin{array}{l}\text { Variance of } \\
\text { Sample mean returns }\end{array}$ \\
\hline Average & $\begin{array}{l}.00379 \\
(3.45)\end{array}$ & .00509 \\
\hline $\begin{array}{l}\text { Fraction of WRSS } \\
\text { profits }\end{array}$ & -- & 1.34 \\
\hline
\end{tabular}

Note: The WRSS is a zero net investment strategy where each stock in the portfolio is assigned a weight equal proportional to the difference between its lagged six-month returns and cross-sectional mean returns. The momentum profit for month $t\left(\pi_{t}\right)$ is computed as:

$$
\pi_{t}=\frac{1}{N} \sum_{i=1}^{N} r_{i, t}\left(r_{i, t-1}-\bar{r}_{t-1}\right) .
$$

where $N$ is the number of stocks in the cross-section, $r_{i t}$ is the return of stock $i$ in six-month period $t$ to $t+5$ and $r_{i t-l}$ is the return in the six-month period $t-1$ to $t-6$. Is the average return across all stocks in the sample.

Autocorrelation consistent $t$-statistic is presented in parenthesis. Cross-sectional variance of mean returns is the variance of sample average six-month returns. In the last column, variance of cross-sectional mean returns is computed excluding the five percent of stocks with the largest and smallest sample mean returns excluded. 


\section{Table 7}

\section{Momentum Profits Adjusted for Sample Average Returns}

\begin{tabular}{|l|l|l|l|}
\hline \multirow{2}{*}{ Calendar months } & \multicolumn{3}{|c|}{ Sample Periods for Mean Return Estimation ${ }^{\mathrm{a}}$} \\
\cline { 2 - 4 } & Pre-Ranking Period & Post-Holding Period & $\begin{array}{l}\text { Pre- Ranking and Post- } \\
\text { Holding Periods }\end{array}$ \\
\hline All & 1.30 & 1.08 & 1.28 \\
& $(6.75)$ & $(5.34)$ & $(6.65)$ \\
\hline January & -2.4 & -2.47 & -2.32 \\
& $(-2.61)$ & $(-2.60)$ & $(-2.57)$ \\
\hline Non-January & 1.64 & 1.40 & 1.61 \\
& $(8.97)$ & $(7.23)$ & $(8.78)$ \\
\hline
\end{tabular}

Note: This table presents the expected returns adjusted difference between monthly returns of extreme winner and loser portfolios classified based on lagged six-month returns. Each portfolio is held for six months. The column titled "Pre-Ranking Period" computes expected returns for each stock as the sample average returns in the period from first month when returns data are available for a particular firm to the month prior to the ranking period. The column titled "Post-Ranking Period" computes expected returns for each stock as the sample average returns in the period from 13 months after the holding period to the last month when returns data are available for a particular firm. The last column computes expected returns for each stock as the sample average returns in the pre-ranking and postholding periods.

a- The sample period is 1965 to 1997 . The sample period for the column titled post-ranking period ends in December 1996. 


\section{Table 8}

\section{Weighted Relative Strength Strategy (WRSS) Profits and Cross-Sectional}

\section{Dispersion in Mean Returns : Simulation Evidence}

\begin{tabular}{|l|l|l|l|}
\hline & WRSS Profits & $t$-statistics & $\begin{array}{l}\text { Percentage of } \\
\text { Momentum } \\
\text { Profits in Actual } \\
\text { Data }\end{array}$ \\
\hline Actual data (1965-1997) & 0.00380 & 3.45 & -- \\
\hline Simulation-with replacement & 0.00410 & 7.35 & 107.89 \\
\hline Simulation - without replacement & 0.00002 & 0.05 & .53 \\
\hline
\end{tabular}

Note: The WRSS is a zero net investment strategy where each stock in the portfolio is assigned a weight equal proportional to the difference between its lagged six-month returns and cross-sectional mean returns. See Table 6 for further details. Autocorrelation consistent $t$-statistic is presented for profits based on actual returns data. The simulation with replacement computes the WRSS profits based on 500 simulations where in each simulation the time series of returns for each stock is scrambled with replacement. The last column reports simulated WRSS profits when returns are scrambled without replacement. 
Figure 1: Long Horizon Momentum Profits Under Different Hypothesis

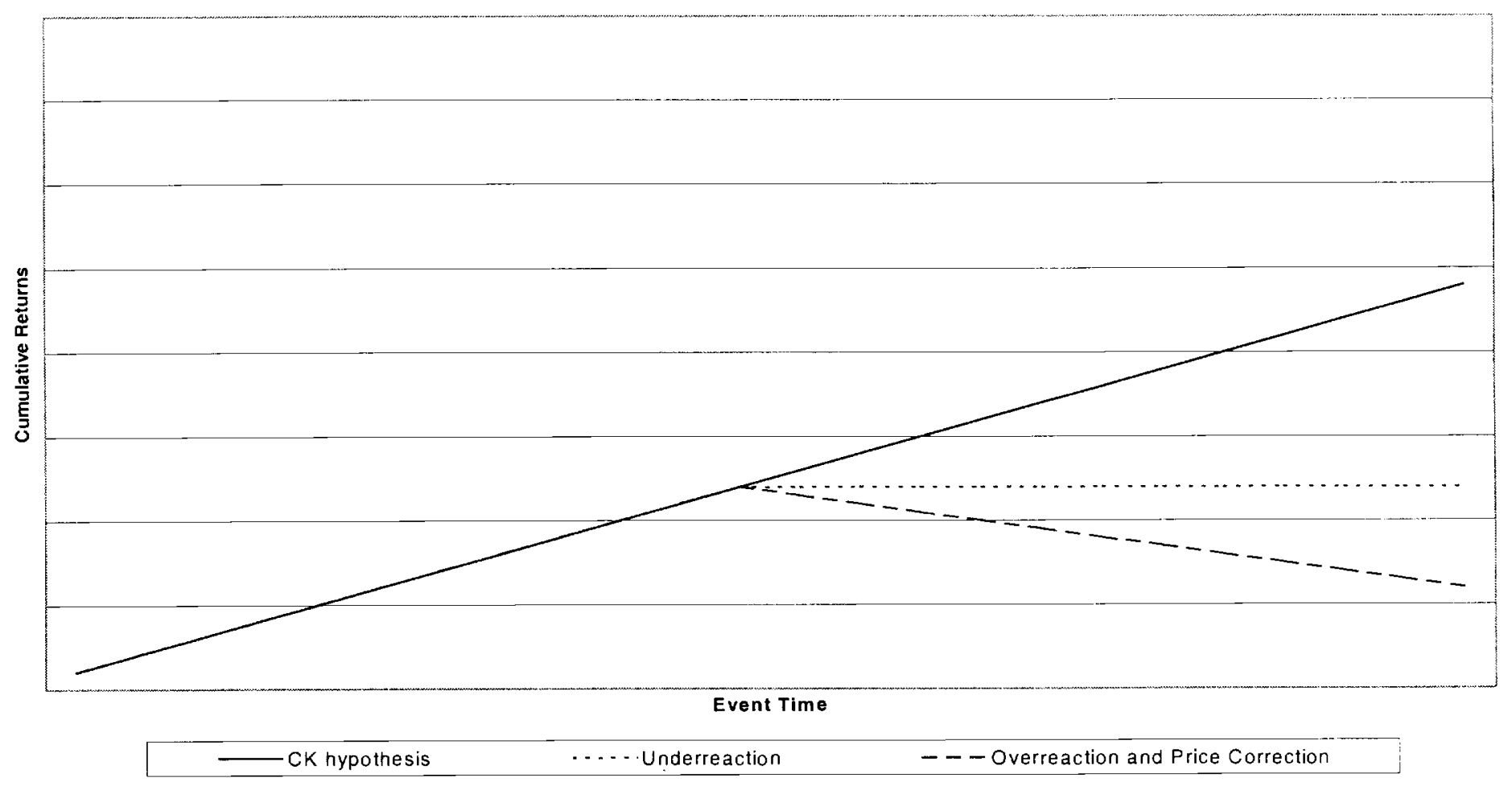


Figure 2: Cumulative Momentum Profits

Figure 1: Long Horizon Momentum Profits Under Different Hypothesis

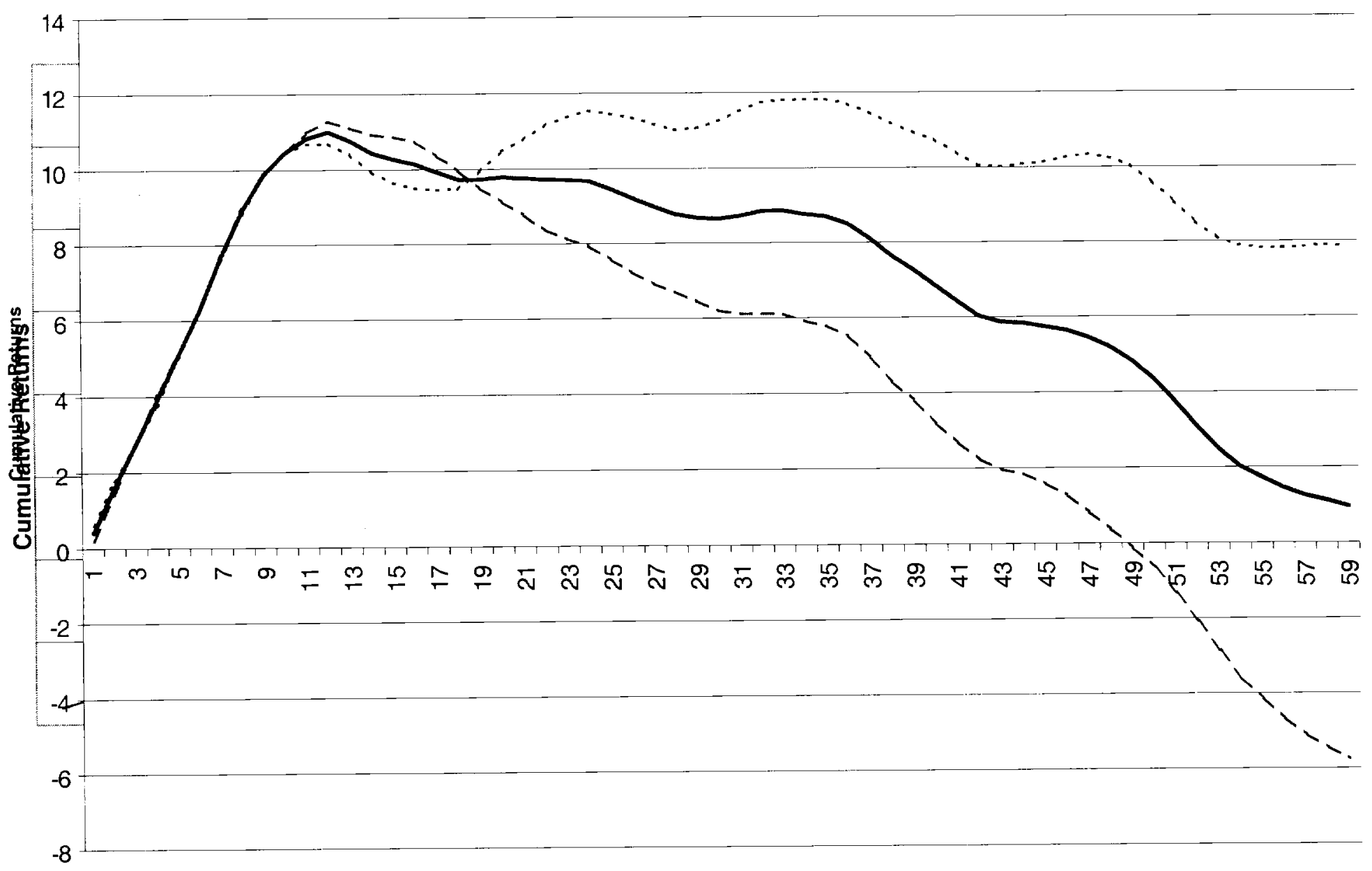

\section{Event Month}

1965 to $1997---1965$ to $1981 \cdots \cdots \cdot 1982$ to 1997 
Figure 3: Distribution of annual mean returns for all NYSE and AMEX stocks in the 1965-1997 period.

\section{Sample average return distribution (\% per year)}

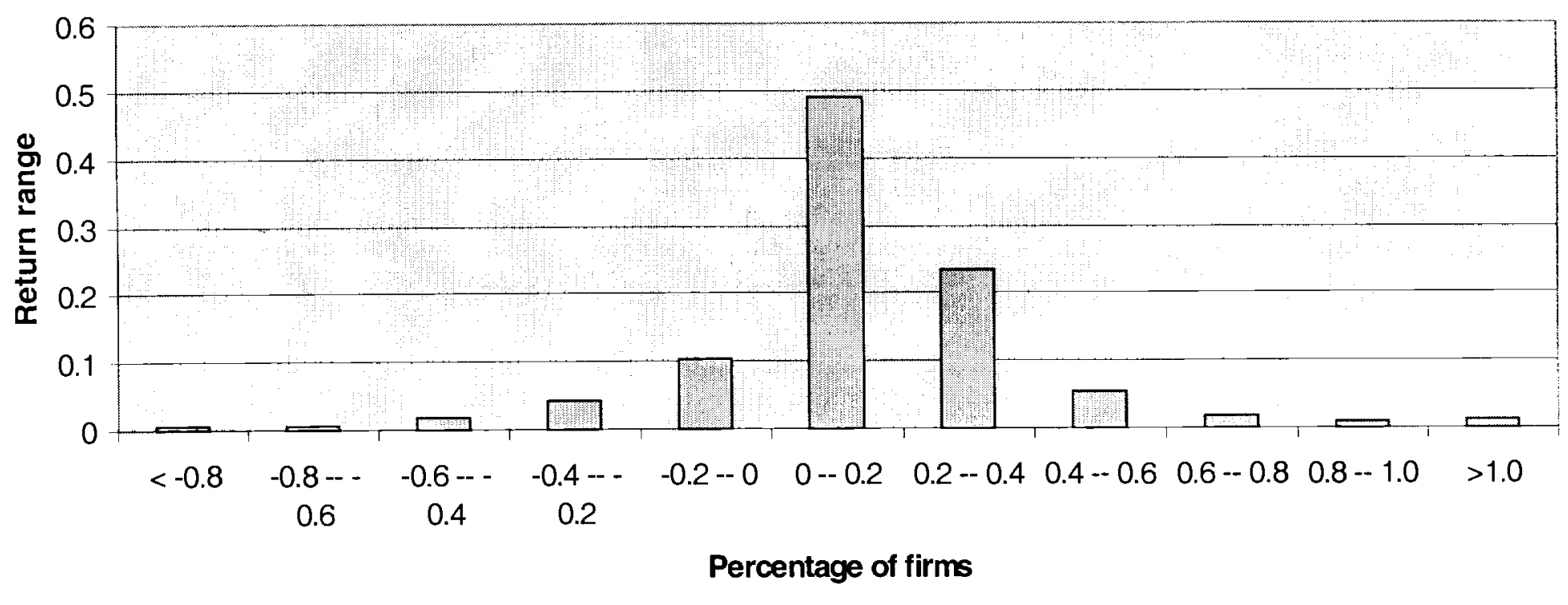

\begin{tabular}{|c|c|c|c|c|c|c|c|c|c|c|}
\hline$<-0.8$ & $-0.8--0.6$ & $-0.6--0.4$ & $-0.4--0.2$ & $-0.2-0$ & $0-0.2$ & $0.2-0.4$ & $0.4-0.6$ & $0.6-0.8$ & $0.8-1.0$ & $>1.0$ \\
\hline $0.62 \%$ & $0.75 \%$ & $1.82 \%$ & $4.18 \%$ & $10.24 \%$ & $49.09 \%$ & $23.54 \%$ & $5.59 \%$ & $1.92 \%$ & $1.06 \%$ & $1.18 \%$ \\
\hline
\end{tabular}




\section{Appendix}

This appendix shows the bias in simulated momentum profits when the simulation is carried out with replacement. It also shows that when the simulation is carried out without replacement there is no bias in simulated momentum profits. Let $r_{i, t}, t=1, \ldots, T$ be the time-series realization of returns for a stock $I$, which under the null hypothesis are serially uncorrelated. Without loss of generality assume that the unconditional expected return is zero for all stocks in the sample.

Consider a simulation experiment that draws returns with replacement and constructs a momentum strategy. Consider a momentum strategy that forms portfolios based on $t-1$ returns, and buys winners and sells losers which are held in period $t$. In this experiment, let $r_{i, t-1}$ be the randomly drawn return for stock $i$ in the ranking period. When returns are drawn with replacement, let $E_{r e p}\left(r_{t} \mid r_{t-1}\right)$ be the expected value of returns for this stock in the holding period $t$, conditional on the return observed in the ranking period. When returns are drawn at random with replacement the probability of drawing any return observation from the time series is $\frac{1}{T}$. Therefore, the conditional expectation of returns drawn during the holding period is:

$$
E_{r e p}\left(r_{i, t} \mid r_{i, t-1}\right)=\frac{1}{T} \sum_{j=1}^{T} E\left(r_{i, j} \mid r_{i, t-1}\right)=\frac{1}{T} r_{i, t-1}+\frac{1}{T} \sum_{j \neq t-1} E\left(r_{i, j} \mid r_{i, t-1}\right)=\frac{1}{T} r_{i, t-1} .
$$

The last equality follows since under the null hypothesis returns are serially uncorrelated and therefore the conditional expectation of returns is zero for $j \neq t-1$.

Momentum portfolios are formed based on ranked $t-1$ returns. By construction losers have low $r_{i, t-l}$ and winners have high $r_{i, t-l}$. Therefore, conditional on the ranking period returns, the expected value of returns drawn (with replacement) in the holding period will be high for past winners and low for past losers. This is true even though by assumption all stocks have the same unconditional expected returns and all returns are serially uncorrelated. So the simulated momentum profits will be positively biased when the simulation is carried out with replacement. How large is this bias? This depends on the length of the return time series. In the limit as $T \rightarrow \infty$ this bias will disappear. However, in our sample, the length of return history is less than 5 years for a large fraction of the stocks. For these stocks there are only 10 independent six-month return observations. Clearly, the assumption that $T$ approaches infinity is untenable, and in fact not necessary. 
If one performs simulation without replacement there is no bias. It can easily be shown, that when returns are drawn without replacement, the conditional expectation of next period's return is:

$$
E_{n o_{-} r e p}\left(r_{i, t} \mid r_{i, t-1}\right)=\frac{1}{T-1} \sum_{j \neq t-1} E\left(r_{i, j} \mid r_{i, t-1}\right)=0 .
$$

